\title{
TRANSPARENCIA Y PUBLICIDAD DE LOS ACTOS ADMINISTRATIVOS
}

\section{Christian Rojas Calderón ${ }^{1}$}

La transparencia y publicidad de la actividad estatal constituye un principio clave para el Estado de Derecho, que constituye garantía para los ciudadanos para evitarles efectos perniciosos producto de la actividad estatal que pudiera de este modo obrar de manera sorpresiva ${ }^{2}$.

Sobre ello también es posible afirmar que la consagración, y sobre todo aplicación de este principio de transparencia y publicidad de la actividad de la Administración, permite obtener de ella razones y criterios de decisión accesibles para todos, pues a todos alcanzaría la posibilidad de consultar cuantos documentos, informes y resoluciones haya podido dictar, constituyendo garantía de crítica pública de su accionar, adecuada preparación y ejercicio de derechos por los particulares y el control de las decisiones administrativas ${ }^{3}$.

Esto, sin duda es reflejo de un concepto democrático de la Administración Pública ${ }^{4}$, y del carácter instrumental de ella, puesta al servicio de la persona humana ${ }^{5}$, desde el cual debe establecerse el régimen jurídico de sus actuaciones, una de cuyas manifestaciones es la producción de actos administrativos.

Abogado. Profesor de Derecho Administrativo de la Universidad Católica del Norte, sede Coquimbo. Correo electrónico: chrojas@ucn.cl

2 Cfr. Cordero Vega, Luis: El Procedimiento Administrativo, LexisNexis, Santiago, Chile, 2003, p. 80 .

3 Cfr. García de enterría, Eduardo y Fernández Rodríguez, Tomás-Ramón: Curso de Derecho Administrativo, tomo II, séptima edición 2000 -reimpresión 2001-, Civitas, Madrid, 2001, pp. 473-474.

4 En efecto, sobre ello se ha dicho -tratando la forma actual de la organización administrativa del Estado- que la organización estatal se ha desprendido de muchas "funciones" que antes le eran "naturales", y hoy escasamente sostenibles pues se han traspasado a los particulares en lo que en general puede caracterizarse como ejercicio privado de funciones públicas; lo que puede perfectamente aplicarse como ideario general a este principio. Para mayores antecedentes sobre lo dicho, véase CORTINASAS-PELÁEZ, León: "De la concepción autoritaria a la concepción democrática en Derecho Administrativo", en REDA, $\mathrm{N}^{\circ} 74$, 1992, pp. 225-254.

5. Artículo $1^{\circ}$ inciso $4^{\circ}$ de la Constitución Política. 
Se ha destacado también, en esta misma línea, que el principio de publicidad es una derivación de la forma republicana de gobierno ${ }^{6}$, como manifestación esencial de este. De modo que la restricción a la publicidad de los actos de la Administración estatal debe ser suficientemente importante y acotada para seguir manteniéndose como excepción a la regla general atendiendo siempre a dos criterios: el primero, que las restricciones deben ser más débiles cuanto mayor sea el interés individual del que pide información; y el segundo, que deben ser más débiles cuanto mayor sea la responsabilidad del solicitante por el buen funcionamiento del ente administrativo requerido ${ }^{7}$.

En fin, al parecer la transparencia es más que la publicidad, pues alude a la actuación diáfana de la Administración estatal en su obrar público, tanto de sus órganos como de los funcionarios integrantes de estos.

Como señala $\mathrm{PAREJO}^{8}$, en el procedimiento administrativo existe una "tensión" entre el secreto y reserva a los que tiende la Administración para el desarrollo de sus actividades; y la publicidad y transparencia como características y técnicas más propias de una Administración estatal puesta al servicio de sus ciudadanos, y sometida plenamente al Derecho en su accionar, Especialmente se manifiesta esta "tensión" o "resistencia" en el acceso al conocimiento de las actuaciones relevantes en el procedimiento administrativo; y en el acceso al conocimiento de los registros y documentos administrativos archivados.

En nuestro país esta materia se encuentra regulada especialmente en dos cuerpos normativos.

Por una parte, en la LOC de Bases de la Administración del Estado9; y por la otra, en la Ley de Bases de los Procedimientos Administrativos ${ }^{10}$.

Al efecto, el artículo 13 inciso $2^{\circ}$ de la LOCBGAE señala que la "(...) función pública se ejercerá con TRANSPARENCIA, de manera que permita y promueva el conocimiento de los procedimientos, contenidos y fundamentos de las decisiones que se adopten en ejercicio de ella".

Luego el inciso $3^{\circ}$ agrega que "son PÚBLICOS los actos administrativos de los órganos de la Administración del Estado y los documentos que les sirvan de sustento o complemento directo y esencial".

\footnotetext{
6 Que en nuestro caso se manifiesta constitucionalmente en el artículo $4^{\circ}$ de la Constitución Política.

7 Cfr. Delpiazzo, Carlos E.: "Control social de la Administración y transparencia", en Ius Publicum, $\mathrm{N}^{\circ} 11,2003$, pp. 46-48.

8 Cfr, Parejo Alfonso, Luciano: Derecho Administrativo, Ariel Derecho, Barcelona, 2003, pp. 715-719.

? Ley 18.575 , actualmente DFL $N^{\circ} 1 / 19.653$ que fijó su texto refundido, coordinado y sistematizado.

10. Ley 19,880 .
} 
También el artículo 14 de la misma LOCBGAE, que regula el denominado AMPARO DOCUMENTAL.

Por otra, el artículo 4 de la LBPA establece que el procedimiento administrativo está sometido, entre otros, a los principios de TRANSPARENCIA Y PUBLICIDAD.

Luego el artículo 16 de la LBPA establece, refiriéndose a dichos principios, que "el procedimiento administrativo se realizará con TRANSPARENCIA, de modo que permita y promueva el conocimiento, contenidos y fundamentos de las decisiones que se adopten en él", por lo que -añade la misma disposición-, "salvo las excepciones establecidas por la ley o el reglamento, son PÚBLICOs los actos administrativos de los órganos de la Administración del Estado y los documentos que le sirvan de sustento o complemento directo o esencial".

Lo expresado normativamente con antelación constituye la manifestación del PRINCIPIO DE TRANSPARENCIA Y PUBLICIDAD que rige los actos de la Administración del Estado.

Todo lo anterior, sin embargo, se ha visto vulnerado o "resistido" por parte de la Administración de Estado.

Ejemplo de ello lo constituye el Decreto $\mathrm{N}^{\circ} 26$ de 2001, del Ministerio Secretaría General de la Presidencia de la República (SEGPRES), que contiene el REgLAMENTO SOBRE EL SECRETO O RESERVA DE LOS ACTOS Y DOCUMENTOS DE LA ADMINISTRACIÓN DEL ESTADO, lo que ha llevado a que un sinnúmero de reparticiones públicas emitan las correspondientes resoluciones por cada servicio que determinaron actos, documentos y antecedentes afectos a secreto o reserva, casi sin limitación.

Ante tal afrenta, y requerida por distintos interesados ${ }^{11}$, la Contraloría General de la República ha emitido distintos dictámenes a este respecto ${ }^{12}$, sosteniendo la general aplicación de este principio.

Particular importancia, por lo expresivo y claro de este, constituye el Dictamen $N^{\circ} 49.883$ de 04 de octubre de 2004 de la CONTRALORÍA GENERAL DE LA REPÚBLICA, que aparece reproducido supra, en donde se sostiene que las resoluciones que dicten los jefes de servicio al amparo del Decreto $\mathrm{N}^{\circ} 26$ de 2001 señalado, destinadas a declarar secretos o reservados determinados instrumentos, deben decir relación exclusivamente con actos administrativos y documentos que le sirvan de sustento o complemento directo y esencial siendo improcedente que se refieran a antecedentes que no revistan ese carácter.

El artículo 8 de dicha normativa reglamentaria funda la posibilidad del secreto o reserva del siguiente modo: "solo podrán ser declarados

11 Particulares pertenecientes a organizaciones ciudadanas, por regla general.

12 Vid. al efecto Dictamen $\mathrm{N}^{\circ} 43.688$ de 2001 y N 2.420 de 2004, ambos en Anexo de VV. AA.: Ley $N^{\circ} 19.880$ sobre procedimientos administrativos, Conferencias Santo Tomás de Aquino, Academia de Derecho, Universidad Santo Tomás, 2003, pp. 222-231. 
como secretos o reservados los actos y documentos cuyo conocimiento o difusión pueda afectar el interés público o privado de los administrativos". Y luego el artículo 9 del mismo reglamento entrega al respectivo jefe superior de servicio, mediante resolución fundada, "determinar los actos, documentos y antecedentes de la institución u órgano de la Administración del Estado que estarán afectos al secreto o reserva".

Se concluye en ella, acertadamente a mi modo de ver, que si bien la regulación del artículo 13 de la LOCBGAE no ampara a los interesados en obtener copia de documentos que no constituyen actos administrativos ni le sirven de fundamento, ello no implica que en virtud de esa disposición estos antecedentes sean secretos o reservados y no puedan o no deban darse a conocer a terceros interesados, toda vez que el principio de transparencia afecta a toda gestión administrativa.

De ello se sigue que la Administración se encuentra obligada a entregar copia de un documento a un particular que lo requiera siempre que ese documento no se refiera a asuntos que revistan el carácter de reservados, y que la información contenida en el antecedente solicitado afecte -es decir, pueda sufrir daño- directamente al particular o se vincule con situaciones fácticas concretas en que le corresponda intervenir.

A través de un cricerio como el expresado se preserva adecuadamente el principio -y la regla general, canon o estándar- en materia de transparencia y publicidad en la emisión de actos administrativos, y de la actividad general de la Administración Pública.

\section{Bibliografía CONSUlTAdA}

- Cordero Vega, Luis: El Procedimiento Administrativo, LexisNexis, Santiago, Chile, 2003.

- Cortiñas-PelÁEz, León: "De la concepción autoritaria a la concepción democrática en Derecho Administrativo", en REDA, $\mathrm{N}^{\circ} 74$, 1992.

- Delpiazzo, Carlos E.: "Control social de la Administración y transparencia”, en Ius Publicum, $\mathrm{N}^{\circ}$ 11, 2003.

- García de Enterría, Eduardo y Fernández Rodríguez, TomásRamón: Curso de Derecho Administrativo, tomo II, séptima edición 2000 -reimpresión 2001-, Civitas, Madrid, 2001.

- Parejo Alfonso, Luciano: Derecho Administrativo, Ariel Derecho, Barcelona, 2003

- VV. AA.: Ley $N^{\circ} 19.880$ sobre procedimientos administrativos, Conferencias Santo Tomás de Aquino, Academia de Derecho, Universidad Santo Tomás, 2003. 